\title{
Discursos y género, en relatos de hombres y mujeres.
}

Discourse and Gender in Stories of Men and Women.

\author{
Por: Elsa María Ortiz Casallas ${ }^{1}$
}

Recibido: junio de 2016 Revisado: noviembre de 2016 Aceptado: noviembre de 2016

\section{Resumen.}

Las mujeres y hombres jóvenes construyen discursos y relatos en base a sus experiencias y cotidianidad, es por eso que sus nociones y maneras de referirse a las realidades están estrechamente ligadas a su género. Estos modos - para este caso- explícitos en categorías léxicas (adjetivos), temas y uso de metáforas, entendidas genéricamente como tropos de pensamiento que vinculan finamente el pensamiento y el lenguaje.

Palabras clave. Análisis del discurso, relaciones sociales basadas en género, formas de pensamiento, experiencias subjetivas

\begin{abstract}
.
Young men and women create speeches and stories based on their experiences and everyday life. That is why their notions and ways of referring to realities, are closely linked to their gender. These modes -for this particular case- explicit in lexical categories (adjectives), topics, and use of metaphors, which are generically understood as tropes of thinking, finely link thought to language.
\end{abstract}

Key words. Discourse Analysis, Gender-Based Social Relationships, Ways of Thinking, and Subjective Experiences.

\footnotetext{
${ }^{1}$ Docente de T.C de la Universidad del Tolima. Ibagué-Colombia, adscrita a la Facultad de Ciencias de la Educación. Licenciada en Lenguas Modernas (Universidad del Tolima), Magíster en Lingüística Española: Instituto Caro y Cuervo; Doctora en Educación, Énfasis lenguaje: Universidad Distrital Francisco José de Caldas. Miembro del grupo de investigación LINGUA, de la universidad del Tolima. Directora del grupo de investigación CONFIGURACIONES, de la Universidad del Tolima, Colombia. Contacto: eortiz112012@,hotmail.com / emortizc@ut.edu.co
} 


\section{Introducción.}

Los jóvenes informantes nacidos en una cultura y partícipes de una sociedad en la que desempeñan roles y establecen jerarquías y distintos tipos de relaciones, enuncian sus discursos sobre la base consolidada de la lengua; ésta, en uso concreto en la sociedad colombiana, ha establecido maneras de decir y de referir los eventos, las cosas y las acciones; ha consolidado ciertas metáforas que se enuncian de manera inconsciente y natural, que reflejan, por lo tanto, la idiosincrasia y el sentir de un grupo humano, que para este caso, lo representan mujeres y hombres jóvenes. Por esta razón, se ha querido analizar las diferencias, o analogías que tienen hombres y mujeres al referirse a diferentes aspectos de la realidad: formas enunciativas que están articuladas directamente con el sistema cultural particular en el que están inmersos.

Para el análisis de los diferentes aspectos de los relatos como: superestructura narrativa, uso de adjetivos, temáticas abordadas y metáforas enunciadas, se tuvieron en cuenta a los teóricos (Van Dijk 2000; Lakoff \& Jhonson, 1986; Denise Jodelet, 1984 \& Moscovici, 1979), entre otros.

Lakoff \& Jhonson (1986), desde una perspectiva cognitiva, se interesaron por el estudio de la metáfora, asignándole y considerándola como un elemento clave para dar cuenta de la comprensión del mundo, y de los mismos individuos; pensamiento que se opuso radicalmente al pensamiento tradicional de corte positivista, el cual le había asignado a la metáfora un papel periférico. La metáfora es un tópico que ha generado grandes tensiones y discusiones desde Aristóteles (2004), con sus obras Poética y Retórica; obras cuyos mismos nombres señalaron dos miradas importantes que aludían a la "función poética" y a la "función retórica", esta última con dimensión persuasiva y argumentativa; aportes de gran importancia que por razones históricas se fueron desviando y reduciendo a funciones ornamentales y a aspectos de sustitución y semejanza, en el marco de la retórica clásica de los siglos XVI al XIX.

Para el común de la gente, la palabra metáfora sólo refiere aspectos de la imaginación poética, algo así como de lenguaje extraordinario, más que ordinario; cosas de palabras, más que de pensamiento y acción. En contraste y de acuerdo con Lakoff \& Jhonson (1986), la metáfora impregna la vida cotidiana, no solamente el lenguaje sino el pensamiento y la acción. Es decir, las metáforas no se reducen al uso de palabras, sino que al enunciarlas reflejan sin ser deterministas, el sistema conceptual particular de los individuos.

Esto es lo que queremos decir cuando afirmamos que el sistema conceptual humano está estructurado y se define de una manera metafórica: las metáforas como expresiones lingüísticas son posibles, precisamente, porque son metáforas en el sistema conceptual de una persona. (Lakoff y Jhonson, 1986, p.42).

El uso de metáforas, según estos autores, no es una cuestión simplemente de lenguaje sino de concepciones y de acciones; la metáfora es, entonces, un fenómeno cognitivo ya que pensar algo en términos de otra cosa es un procedimiento cultural general que los individuos realizan para volver inteligible y comprensible algo que resulta imposible de conceptualizar. Desde otra perspectiva y de forma similar, la teoría de las representaciones sociales posiciona el agenciamiento de sujetos en tanto constructores de realidades sociales que intentan materializar mediante la palabra; actores capaces de negociar y convertir en imágenes figurativas y concretas aquello que es abstracto (Jodelet, 1984). En la construcción del conocimiento este proceso es 
ampliamente conocido como objetivación y anclaje (Piaget, 1974; Moscovici, 1976; Jodelet 1984) "Objetivizar es reabsorber un exceso de significados materializándolos" (Moscovici, 1976).

Desde el punto de vista de los anteriores teóricos, la investigación en este campo resulta ser fundamental toda vez que permite desentrañar y desenmascarar aquellas formas de decir y actuar que socialmente se van estructurando y naturalizando vía comunicación e interacción social; algo que como afirma Bourdieu (1980), el pensamiento práctico procura. Se trata, entonces, de volver inteligible y comprensible aquellos fenómenos de la cultura que los sujetos socialmente han asimilado de forma inconsciente y natural, olvidando su carácter artificial, lo cual hace imposible la confrontación, la problematización y la sospecha (Nietzshe, 2000). En este sentido, el fin último de la investigación sería la reflexión, la resignificación y la transformación de representaciones y prácticas en donde el uso de metáforas, en tanto tropos del lenguaje y fenómenos conceptuales, juegan una función importante en dicha transformación y en la construcción de un pensamiento crítico (Jodelet, 1984).

\section{Metodología.}

Se llevó a cabo un análisis de contenido a los relatos, y se realizó un procedimiento hermenéutico de comprensión y explicación de las diferentes categorías objeto de estudio: superestructura narrativa, uso de adjetivos, temáticas y uso de metáforas.

El corpus se recogió en la ciudad de Bogotá; son 20 relatos: 10 de mujeres y 10 de hombres, cuyas edades oscilan entre 18 y 23 años.

\section{Resultados.}

\section{Superestructura Narrativa De Los Relatos.}

Según Bajtin (1982) la diversidad de los géneros discursivos es infinita porque las posibilidades de la actividad humana son inagotables. Este teórico divide los géneros en primarios y secundarios y ubica los relatos en el primero, dado que es un género oral que se da en la espontaneidad de la vida cotidiana.

Se observa cómo la experiencia del mundo (mimesis 1), se convierte en experiencia simbólica (mímesis 2) para ser interpretada y comprendida (mímesis3), (Ricoeur, 1981). Todos los relatos, de manera general obedecen a una intencionalidad, cuyo propósito es contar unos acontecimientos ligados a la experiencia propia o a la de personas muy próximas. Por lo tanto, los hechos dan cuenta de vivencias cargadas de emotividad y sentimientos; esto se desarrolla a través de la enunciación de secuencias de proposiciones que van desde un punto inicial del relato, se desarrollan en una trama y se definen en un final.

Según Labov (1988), una narrativa consta de las siguientes partes: Síntesis, orientación, acción complicante, evaluación y coda. Dado que las narraciones estaban condicionadas por la pregunta ¿cuál ha sido el momento más importante de su vida?, remiten a una narración en primera persona, incluso cuando no es protagonista de la historia; igualmente, implica la evocación de recuerdos y la referencia al pasado, la ubicación en un presente y la proyección de un futuro. Asimismo, la extensión del relato se limita a la solicitud expresa del tiempo: 5 minutos. 


\section{Mujeres.}

En relación con la estructura básica de las narraciones, llama la atención que la tendencia de las mujeres objeto de este estudio es a desarrollar narraciones con temáticas que implican aspectos negativos como la muerte, vicios, enfermedades, rupturas y en general obstáculos. Estas evidencian una carga evaluativa llena de valores, temores, prejuicios, propios de nuestra cultura.

Desgraciadamente uno como ser humano, no, no presta atención a lo que se, se le dicen y se le advierte y se le da como un consejo y lo toma más como un regaño y como algo que no le va a servir $(. .$.

(...) Entonces, eso fue tenaz, fue muy difícil. Mi mamá ha sido la hija consentida de la casa, por ser mujer y eso fue (E1)

Nótese que en las intervenciones, especialmente en la última, persiste el imaginario cultural de seguir un modelo, ¿cuál modelo? El que ha instaurado la cultura moderna, aquel que disciplina la formas de pensar, decir y hacer. Las mujeres en este caso, como se evidencia en los ejemplos, deben renunciar a su sexualidad, ser juiciosas, consentidas, y responsables; deben ser, además un ejemplo y un modelo de vida. Se perpetúa, de esta manera el orden establecido.

\section{Hombres.}

A diferencia de las mujeres, solamente un hombre de los 10 participantes de este estudio, desarrolla en la narración una temática negativa. Los demás, aunque durante la trama lo hagan, no es el hilo conductor de sus relatos. Dado que sus temáticas fueron diferentes a las mujeres, no hablan mucho de la necesidad de seguir modelos, sus relatos remiten más a ser protagonistas de eventos, viajes, anécdotas; sin embargo, también hacen evaluaciones de tipo moralista, comentan prejuicios, tienen en cuenta valores universales como la humildad, la solidaridad, tener una familia, una educación.

Aprendí que uno puede ser una parte valiosa en la vida de otra persona y el poder ayudar a los demás es fundamental, así le paguen mal a uno (...)

Creo que algo que aprendí fue a aprender a tolerar, a ponerme en los zapatos del otro; también fui, tengo que decirlo así, fui un poquito relegado por mucha gente por mi condición social (...) y lo iban relegando, digamos lo iban apartando mucho $(. .$.

Tal es la base conceptual cultural y experiencial de los sujetos a la cual hace referencia Lakoff \& Jhonson (1986), cultura que responde a ciertos imperativos, valores, y habitus como los mencionados en los ejemplos. El catecismo dice: Dios hizo al hombre a su imagen y semejanza, pero el hombre al pecar perdió la semejanza, conservando siempre la imagen. Ahora bien, llama la atención la forma como todos, tanto hombres como mujeres cierran los relatos (coda). Las codas tienen la propiedad de cerrar la brecha entre el momento al final de la narrativa y el presente (Labov, 1988). Es decir, la referencia temporal del discurso se reestablece en el presente; entonces la pregunta que se podría hacer cuando alguien termina de narrar es: "qué pasó entonces"; la respuesta "Nada aquí estoy". En el análisis se observa que la mayoría de cierres son: "nada aquí estoy luchando, pensando que todo puede mejorar, cambiar" Veamos: 


\section{CODA MUIERES}

"entonces ha sido dificil pero pues yo creo que eso me ha ayudado también a ser mejor" "pero no ahi vamos, con muchos ánimos; aprovechen el colegio y háganle adelante" "y que cada día y cada cosa que haces sirva para Dios, ese ha sido el suceso más importante de mi vida y esas son las razones por las que fue el suceso"

"Entonces, Igual, cualquier experiencia que uno tenga pues bienvenida para su vida. La idea es que todo puede mejorar"

"peroya después como familia todos, no, que tranquila, la apoyamos mucho y ya. Creo a esto época está superado un poco, pero pues el recuerdo sigue ahi y es un angelito para todos nosotros"

"eso fue un momento espectacular, a pesar de que me ha ayudado muchisimo también" "yo queria estudiar licenciatura y por eso para mi era muy importante ingresar a la

Universidad Distrital.

\section{CODA HOMBRES}

" $y$ ho sido una de las cosas más importanteso esta es una de las cosas más importantes - la academia y creo que puedo ser mejor" "y ahi mismo yo quiero seguir estudiando, yo quiero terminar el once y quiero terminario. $Y$ asi esa es la versión"

"una experiencia que a partir de ella aprendi que uno puedo ser una parte valiosa en la vida de otra persona y el poder ayudar a los demás Engeneral seria eso"

"yo creo que para mi fue como sentarmey pensar en mi mismo y sólo pensar en mi una sola vez, en mi futuro con optimismo claro" "Emplezo, yo a definir mi vida, ya no que otras personas entraran $a$, $a$ definirla o a 0 a alterarla sino soy yo otra vez con, con mis metas. Ese fue como el momento asi cumbre" "en algún momento de la vida tengo que mirar al lado mio y ver quien está, qué le está pasando a esas personas $y$ anhelar un entorno nacional un poquito más estable... bueno, eso prócticamente eso.

Imagen 1 Fuente: Elaboración propia.

Los seres humanos vivimos dentro de una especie de axiomas que se van internalizando y se vuelven incuestionables; son modelos de identificación y supervivencia que se construyen histórica y sociológicamente. A partir de lo anterior, es pertinente preguntar por qué los sujetos caen en comportamientos tan recurrentes, algo importante para ahondar en la lógica del pensamiento social. Lo más grave es que el pensamiento tautológico hace que repitamos los mismos esquemas, los mismos caminos y fracasos. En esta línea, se observa en la resolución de los relatos una fe ciega en el futuro, en el progreso; y es algo que deviene de la instauración de la cultura moderna; el mito del progreso y el fantasma del eterno retorno como creencia del porvenir: "El eterno retorno en este sentido es el devenir-loco dominado, monocentrado, determinado a copiar lo eterno" (Deleuze, 1989, p. 265).

\section{Marcadores Léxicos.}

En este apartado se analizarán los adjetivos para desvirtuar la hipótesis que ronda culturalmente acerca de que las mujeres son quienes más adjetivan con marcas léxicas muy específicas, lo cual conlleva a suponer que son más emotivas y sentimentales que los hombres a la hora de relatar sus experiencias. Existen, incluso muchas investigaciones que ratifican este imaginario (Pearson et al, 1993). Este aspecto se reitera en los otros capítulos y constituye una manifestación importante en este ejercicio.

El análisis cuantitativo de los relatos mostró las siguientes cifras: los hombres calificaron los eventos, acciones u objetos con 128 adjetivos y las mujeres con 102. En los dos casos muchos de ellos están precedidos por adverbios como muy, super y bastante, fundamentalmente. De otro lado, hubo relatos masculinos cargados de adjetivos como relatos femeninos desprovistos de 
ellos o viceversa. En el relato donde el joven narra el nacimiento de su hija hay 27 adjetivos, y donde se narra sobre el atraco hay solamente 2; igualmente en un relato de una joven que narra sobre la muerte de su padre, solamente se califica con un adjetivo; mientras que en otro del mismo género en el cual se narra sobre la conformación de su familia a los 14 años se evidencian 20 adjetivos. De igual manera, con esto se relativiza el imaginario de que las narraciones de las mujeres están impregnadas de mucha carga sentimental y afectiva y la de los hombres no.

Los hombres emplean adjetivos que aparentemente serían femeninos como rico, delicioso, curioso, bonito, especial y feliz: "Me pareció bastante rico, muy interesante"; "que yo me sentí feliz, me sentí contento, me sentí pleno fue en el momento en que me invitaron a viajar a Argentina"; "Era una sensación extraña porque era, pues, la sensación de tristeza por ya retornar al país pero era una sensación muy alegre". "El pelao se veía muy bonito diciendo eso"

\section{Temas y género.}

La siguiente tabla muestra las tendencias temáticas en hombres y mujeres:

\begin{tabular}{|l|l|l|}
\hline TEMAS & HOMBRES & MUJERES \\
\hline Estudio & 3 & 4 \\
\hline Familia & 2 & 5 \\
\hline Viajes & 3 & 0 \\
\hline Anécdota & 1 & 0 \\
\hline Trabajo & 0 & 1 \\
\hline Religión & 0 & 1 \\
\hline
\end{tabular}

Tabla 1 Fuente: Elaboración propia

En general se trataron 6 temas. Los temas están directamente relacionados con el estudio, la familia, el colegio, el trabajo, anécdotas y viajes; temáticas que tiene que ver con las expectativas y con las edades en que se encuentran los informantes. De los seis temas tratados, hombres y mujeres comparten sólo dos: estudio y familia, y difieren en temas como los viajes, anécdotas y trabajo. La pregunta a responder en este apartado es: ¿qué dicen los hombres y mujeres al respecto de cada uno de los temas tratados?

Estudio: Tres de los diez hombres y cuatro de las diez mujeres hablaron de estudio. Dos de los tres hombres hablaron de este tema como hilo conductor de sus relatos. Uno de ellos se refirió al momento cumbre del bachillerato: la graduación; contó la importancia que tuvo para el ser el mejor y mencionó con orgullo una anécdota significativa. El otro habló de su trayectoria en la universidad, de su estrato social (clase media), de los momentos importantes que allí vivió y de la madurez que adquirió en este espacio.

En relación con las mujeres, la diferencia en cuanto al tratamiento de la temática fue significativamente diferente. Para las cuatro mujeres el estudio, la formación, el ser profesionales es un aspecto central en sus vidas. Las cuatro se refirieron a la academia en la universidad y una de ellas, con mayor énfasis que las otras, se refirió a la universidad como un sitio de libertad, de compartir en otros espacios que no fueran de "el colegio a la casa y de la casa al colegio (...)" Todas se refirieron a la academia como algo vital en sus proyectos de vida, y mostraron su inclinación hacia la formación docente. Para ellas, el haber aprobado todos los grados escolares, 
desde primaria hasta el bachillerato y luego ser licenciadas son logros de gran trascendencia y superación personal.

Como puede observarse, hay marcadas diferencias en el tratamiento de esta temática. Los hombres hablan del estudio como un aspecto seguramente importante es sus vidas, pero no vital. El estudio los remite a otras metas, espacios, o vivencias, menos o más importantes que la academia. En este sentido el hecho de estudiar, para las mujeres constituye un elemento trascendental; es decir, forma parte de su proyecto de vida.

La Familia: Este fue el tema más recurrente en las mujeres. De 10, 5 hablaron de familia, y de los 10 hombres sólo 2 se refirieron a este tema; uno de ellos como pretexto para hablar de sus anécdotas en la calle. De las 5 mujeres, 4 hablaron de la familia y tematizaron sobre la muerte de un ser querido. Llama la atención que las mujeres, en estos relatos, inician siempre con un aspecto negativo y concluyen con una evaluación positiva: "Y aquí voy súper, súper, súper con muchas ganas de salir adelante, pero ahí vamos, con muchos ánimos, aprovechen el colegio y háganle adelante" (E3).

A pesar de que sólo 2 hombres hablaron de familia, uno de ellos contó, quizá con más contundencia que las mujeres lo que según él partió su vida en dos: el nacimiento de su hija. Este relato leído de forma anónima se podría confundir fácilmente con el de una mujer; allí relata con mucha emotividad y sentimiento lo que significó la llegada de su bebé: "Marcó mi vida para siempre... lo más hermoso, lo más cercano al cielo y es el nacimiento de ese bello ángel...me dio lo que las mujeres llaman una corazonada (...)" (E4)

Trabajo: Sólo una mujer habló de trabajo, pero no como una actividad económica fundamental en su vida, sino como una actividad que le permitió compartir con otras personas desde la perspectiva de los valores, el respeto, la ética. El trabajo como una actividad que le permitió aprender bastante, establecer una relación entre la práctica y la teoría y viceversa.

Lo más importante fue que me brindó la oportunidad de aprender muchísimo de otras personas (...) pues también tiene que tener en cuenta sus valores y el hecho de que uno debe estar feliz haciendo lo que le guste (...) ese trabajo me sirvió para guiarme. (E6)

Por su parte, los hombres no tematizaron propiamente sobre el trabajo, no obstante, lo refieren marginalmente en sus relatos como la actividad que les proporciona recursos económicos.

Me convertí en el guía turístico el que orientaba los turistas pero que manejaba los caballos de las cabañas, ese era el oficio que tenía que desempeñar mientras que los amigos con los que estábamos trabajaban como recepcionando a las personas que llegaban al hotel, otros arreglaban las camas las cabañas (E7)

Religión: Una de las informantes se refirió al tema religioso. Habló de la manera como inició en la religión Testigos de Jehová, las razones de su continuidad, la importancia para su vida y para los demás; ve la religión como un hecho importante que guía la vida de las personas y crea valores. Esta temática no fue abordada por ninguno de los 10 hombres. 
Viajes: De los 10 hombres 3 hablaron de viajes, diferencia significativa en relación con las mujeres pues ninguna de ellas abordó esta temática. En los 3 relatos los hombres mencionan los viajes que han realizado, las experiencias y las anécdotas allí vividas. Para ellos salir, conocer lugares, personas y tener aventuras parece ser muy importante. Esta temática marca notoriamente diferencias de género. En los relatos de las mujeres, los viajes no revisten importancia.

Anécdotas: Sólo un hombre habló de una anécdota que le sucedió cuando estaba prestando el servicio militar. Se centra en el accidente que ocasionó una buseta a un señor que pasaba en una bicicleta, en su capacidad para solucionar el problema, en la buena suerte que lo acompaña en el accidente, en el proceso de conducir al hospital al accidentado y, en el final feliz que tuvo. Aunque en la mayoría de relatos masculinos tocan temas importantes, la manera de narrarlos es diferente a la narración de las mujeres; ellas le dan un matiz más esencialista y los hombres más circunstancial, por ello sus relatos cuentas hechos anecdóticos.

Los anteriores resultados en cuanto a los temas y tópicos coinciden con algunas investigaciones que indican que los hombres prefieren hablar de temas impersonales, viajes, anécdotas, contrario a las mujeres quienes se inclinan por hablar sobre asuntos personales, familiares, y sentimentales.

\section{Género Y Metáforas.}

\section{-Metáforas De Orientación.}

Las mujeres utilizaron con mayor recurrencia que los hombres las metáforas orientacionales; de manera reiterativa hablan del pasado, del presente, del futuro, de lo que pasará más adelante. Las más frecuentes son:

Bueno Es Arriba, El Poder Es Arriba: Existen en nuestro lenguaje una serie de expresiones en tanto que metáforas lexicalizadas que indican que estar arriba es bueno y que tener poder significa estar en lo alto. Estas metáforas no son arbitrarias pues están basadas en la experiencia física y cultural de los sujetos sociales. Palabras como crecer, superar, escalar, mejorar hacen parte del ideal moderno e ilustrado de la cultura; la fe en el progreso, propio de la modernidad, ha instaurado en los individuos la idea ciega en el; así no se progrese estar arriba es bueno, cueste lo que cueste.

Tener ascensos laborales, crecer como personas, superar los problemas y creer en Dios (Dios está arriba), son aspectos principales en la vida de las mujeres: "A pesar de que haya de pronto ascensos laborales", "que las cosas que haces van a servir para crecer como persona, para ayudar a crecer a los que te rodean", "está superando un poco", "Es necesario insistir, si hoy no fue mañana será mejor", "Y me alzó de la cama como alzan una reina (...)".

Hombres: "creo que es lo más significativo, los más espiritual, lo más cercano al cielo si es que existe.", "Nosotros tuvimos un ascenso económico.", "lo aplasté con mi comentario".

Nótese en este último ejemplo lo que significa tener el poder, aplastar no sólo es vencer, sino vencer con gran diferencia. Estar abajo no es bueno, ni mucho menos minimizado y aplastado. Hablar de sociedad es hablar entonces de relaciones de poder, un conjunto de clases organizadas jerárquicamente: "La metáfora concreta algo abstracto: lo abstracto de las elaciones de poder lo 
remitimos a algo concreto como es la situación física de algo que está arriba de otra cosa" (Díaz, 2006).

E1 Estudio es adelante, adelante es positivo: Caminar y mirar hacia delante hace parte de nuestra experiencia física occidental; éstas orientaciones espaciales esquemáticas y paradigmáticas influyen de manera natural en los sujetos quienes de igual manera van asimilando y asignando de manera irreflexiva, práctica y causal significados en su cultura (Grice, 1977). Desde el proyecto de modernidad occidental, estudiar ha significado siempre salir de la ignorancia, la pobreza y la marginalidad, y así lograr ser ciudadano y contribuir con el orden social impuesto (Chartier 2000; Olson 1998). El estudio, en este caso, es entonces índice de superación, civilización, desarrollo y productividad, así la historia nos haya demostrado que no siempre ha sido así.

Las mujeres hablan mucho del estudio como un aspecto fundamental en sus vidas que les permite salir adelante: "La educación era el primer paso hacia, hacia la profesionalización"; "Tenía el ideal de ser maestra"; "siempre tenía pensado ser maestra"; "mi proyecto de vida iba encaminado hacia la formación docente"; "me estoy mentalizando a que en unos años, el logro de mi vida será graduarme, que es lo que más aspiro"; "El grado que yo tengo, era de las mayores aspiraciones desde muy pequeña, siempre tenía pensado ser maestra"; "desde el primer día de clase (...) siempre me visualice a llegar muy lejos a llegar muy lejos a nivel educativo". Las mujeres, en este caso tienen metas y propósitos bien definidos que les permiten visualizar y orientar hacia adelante sus vidas: "siempre me visualicé llegar muy lejos, siempre pensé terminar quinto, terminar el colegio, terminar el bachillerato y llegar a la universidad"; "de pronto en unos años esto va a cambiar (...)", "mi norte ha sido siempre estudiar"

De igual manera los hombres consideran que estudiar es importante para salir adelante, trabajar y ser productivos: “(...) ahí mismo yo quiero seguir estudiando, yo quiero terminar el once y quiero terminarlo" (E10)

En general, el pensamiento occidental y el lenguaje han sido construidos sobre un sistema de diferencias organizadas y un método de oposiciones binarias: dicotomías como las encontradas en los anteriores ejemplos: arriba/abajo, adelante/atrás, sagrado/profano, pasado/presente, norte/sur, en donde, el primer término es privilegiado y designado como la norma del significado cultural, creando una jerarquía dependiente y marginal, "El segundo término realmente no existe fuera del primero, sino que existe dentro de él, aunque la lógica falocéntrica de la ideología supremacista blanca nos haga pensar que existe fuera y en oposición al primer término" (McLaren, 1997, p.158). Binarismos, que en tanto constituyen la base conceptual cultural de los sujetos, actúan como modalidades constitutivas de sentido, difícilmente de subvertir.

Activo es positivo, pasivo es negativo, el tiempo es oro: Uno de los paradigmas de la sociedad capitalista es que "el tiempo es oro". En la cultura capitalista nadie puede estar quieto, todos deben ser activos, trabajar y ayudar a reproducir el statu quo. En contraste, con la antigua cultura griega, en la nuestra no hay tiempo para el ocio; es necesario hacer más y en menos tiempo. En el análisis se encuentra que esta metáfora es más utilizada por los hombres, quizá por el imaginario histórico social, el cual supone que el hombre es la cabeza de la familia y es quien debe trabajar. Hablan, por ejemplo de rebuscar, volver a hacer cosas, insistir, trabajar como algo fundamental en sus vidas: "Y me ha tocado revolar por ahî"; "Y horita trabajando y todo eso"; "Yo quiero seguir estudiando (...)"; "Y era volver a colocarme objetivos, era volverme a colocar

\begin{tabular}{l|l|l|l|l|l|l} 
AGO.USB & Medellín - Colombia & Vol. 17 No. 1 & PP 1 - 323 & enero - junio & 2017 & ISSN: 16578031
\end{tabular} 
metas (...) asumir cosas nuevas"; "Y era como replantear otra vez mi vida, con un nuevo trabajo"; “(...) he entregado eee infinidades de trabajo e de trabajos, he trasnochado,".

En los relatos de las mujeres se percibe que son personas inquietas, activas y prefieren trabajos que tengan que ver con la formación; por eso aparece en sus relatos la educación, como se puede apreciar en la metáfora: "El estudio es adelante". Esto refleja de alguna manera, la idea de la mujer como esencialmente educadora y formadora de valores en la cultura.

\section{-Metáforas Ontológicas.}

Los sujetos sociales comúnmente tratan la cultura como un producto y no como un proceso, por ello personifican u ontologizan la realidad social y le dan status fáctico, lo ven como algo que está ahí, independientemente de su aprehensión; sólo en circunstancias determinadas la interpelan, o la problematizan (Bourdieu, 1980). Lakoff \& Jhonson (1986) indican al respecto: "Son tan naturales e impregnan tanto nuestro pensamiento que normalmente se consideran descripciones directas o autoevidentes de fenómenos mentales" (p.67). Dentro de las metáforas ontológicas aparecen las siguientes:

Los lugares son recipientes: Tanto mujeres como hombres mencionaron bastante los lugares como recipientes; sin embargo, en cada caso el tratamiento fue diferente. Las mujeres toman como lugares recipiente fundamentalmente la casa, la escuela y la universidad. Las dos primeras la toman como cárcel, encierro y la última como espacio de libertad. Las mujeres entran y salen de estos lugares: de la casa al colegio, del colegio a la universidad, de la universidad a la calle y de la calle al hogar: "siempre fue del colegio a la casa y de la casa al colegio, pero nunca me dio espacios para salir, entonces al entrar a la universidad (...)". Obsérvese el habitus que van construyendo las mujeres: casa-colegio-universidad-hogar y luego ellas pasarán a ser recipientes de hijos.

Por las mismas razones culturales, los hombres además de tomar como lugares-recipiente la casa, el colegio y la universidad, mencionan la calle, las ciudades y los lugares que visitan. No hacen la diferencia entre lugares de encierro y lugares de libertad: "El entrar a otro país, para mí, era volver a nacer (...)"; "en ese tiempo en que estuve fuera del país, fue en el momento en que llegué a a otra vez a Colombia"; "sentí muchas ganas como de salir al teléfono"; "nos fuimos en el bus...llegué a la casa"; "Y corra y corra cuando me metí en la tienda de un amigo"; "entramos al hospital, hablé y le dieron la entrada"; "estuvimos en muchas poblaciones"; "me tocó salirme de la casa como un año, de trabajar fuera de Bogotá"; "Ellos se metieron así por una cuadra de unos amigos". El esquema conceptual indica que los hombres son de la calle, aventureros y las mujeres son de la casa.

Las personas son recipientes: Desde la perspectiva del consumo, los sujetos son vistos como recipientes que deben ser llenados con conocimientos, responsabilidades, metas; en este caso la educación es esencial para la reproducción de la ideología dominante (Freire, 2004).

Las mujeres, en general, se refieren a las personas como recipientes, y en particular a las mujeres como receptáculo de conocimientos, aprendizaje, dolor, felicidad, expectativas, responsabilidad, metas, experiencias, recuerdos, principios, llanto e hijos. Todo el tiempo hablan de aprender, de adquirir conocimientos y experiencias: "Aprendí muchos conocimientos que hoy me han ayudado mucho"; "he aprendido a crecer tanto"; "aprendí a querer a mi mamá”; "el

\begin{tabular}{l|l|l|l|l|l|l}
\hline AGO.USB & Medellín - Colombia & Vol. 17 No. 1 & PP 1 - 323 & enero - junio & 2017 & ISSN: 16578031
\end{tabular} 
recuerdo sigue ahí"; "Y aprendí otras cosas más"; "fue un trabajo en el cual yo aprendí muchísimo"; "Aprendí mucho a tener más responsabilidades"; "mi hermana empieza con sus dolores de parto" Los hombres no hablan tanto de ellos como recipientes de aprendizaje, formación y educación, sino como recipientes de experiencias, aventuras, felicidad, rabia, temor y miedo. Es pertinente anotar que la forma como los hombres narran los sentimientos no se diferencia mucho de las mujeres y consideramos que, en algunos casos, como los aquí mencionados son más contundentes los hombres que las mismas mujeres: "Ya llegando otra vez a Bogotá eh...no pude contener las lágrimas, o sea, en los ojos”.

Las personas son edificios: Las mujeres, más que los hombres, se refieren a ellas mismas como objetos, en este caso, como edificios con bases que necesitan de apoyo, soporte y ayuda para sus proyectos de vida: "Aprendí a querer a mi mamá como la mujer más grande que tengo y como la ayuda y el soporte para yo respirar todos los días"; "Uno siempre necesita digamos del apoyo de una parte femenina y una masculina, pero yo creo que eso me ha ayudado también"; "Yonny no me apoyaba mucho"; esas personas te van a ayudar a construir como persona". Por su parte los hombres se consideran más como generadores de apoyo: "Y el poder ayudar a los demás, en general sería eso"; "mi papá se separó de mi mamá y desde esa a veces a mí me ha tocado para ayudarle a mi mamá, a mis hermanos me ha tocado revolar por ahí". Nótese que los anteriores ejemplos muestran las representaciones sociales que existen en la cultura sobre el hombre y la mujer. La mujer es siempre frágil, débil; por lo tanto, necesita de alguien que la apoye, generalmente de un hombre.

Personificación: los objetos son personas: Dado que la personificación forma parte de las metáforas ontológicas y estas "entienden nuestra experiencia en términos de objetos y sustancias" (Lakoff\& Johnson, 1986: 63), entonces para este estudio se agrupan todas las subcategorías de personificación en una jerarquía mayor que se denomina: los objetos son personas, para significar que un hecho, situación, institución, lugar, objeto o cosa, toma características humanas para delimitarse.

De manera general y con una ligera diferencia, los hombres las usan más que las mujeres. Veamos algunos ejemplos: "La experiencia cuenta que nos fuimos por 15 días"; "por más de que yo me esforzara el trancón no salía"; "se alcanzó a mover el flujo"; "Fue muy curioso (lo que sucedió)"; "es bastante especial (...) es gracioso también aparte de especial"; a pesar de que de pronto uno tenía el estigma de ser colombiano"; Y las mujeres: “(...) todos los problemas que se dirigen digamos hacia mi mamá"; "rescato, rescato este momento porque creo que los demás han sido pasajeros (el estudio)".

E1 amor es un objeto: En la cultura occidental capitalista, el amor se convierte en un objetivo a alcanzar, es decir en un objeto deseado. En este sentido la persona amada se cosifica en tanto objeto de consumo. El objeto amor personificado suscita posesión. Bajo este esquema cognitivo tienen sentido las siguientes metáforas enunciadas en mayor medida por las mujeres: "Él era mi amor", "Cuando él me rechazó, sentí un dolor profundo" "Él nunca me quiso". Los hombres hablan en menor medida de sus experiencias amorosas y tratan de no evidenciar sus derrotas amorosas. Bajo esta idea el amor se esquematiza así: posesión, consumo, sufrimiento; y los individuos van asumiendo acríticamente que ese es el único modelo para amar, sin entender que ese ha sido una construcción social-histórica susceptible de ser revisada y resignificada. 


\section{-Metáforas estructurales.}

Las metáforas estructurales permiten utilizar un concepto estructurado para constituir otro: "Las metáforas estructurales se fundamentan en correlaciones sistemáticas de nuestra experiencia" (Lakoff \& Johnson, 1986, p.102), veamos:

La vida es un camino: Esta gran metáfora involucra cualquiera otra por cuanto en la vida acontecen todo tipo de situaciones. El concepto de 'camino' estructura las experiencias que el ser humano tiene durante su existencia. Tanto hombres como mujeres se refirieron a la vida como un camino que se va haciendo, pero en las mujeres fue mayor el énfasis; éstas casi todas hablan de las experiencias que han marcado su vida: "Lo que más me ha marcado el camino (...)"; "me parece una de las más importantes y que ha marcado los caminos que yo sigo (...)"; "Lo más importante fue que me guio a lo que realmente yo quiero"; "Porque marcó el derrotero que yo he llevado hasta el momento". De los 10 hombres, sólo dos hablaron de cómo los marcó la vida: "Voy a contar un acontecimiento especial en mi vida, yo creo que uno de los acontecimientos que más me marcó eh fue la entrada a la universidad". El resto de hombres hablaron en menor proporción de la vida como un camino: "No solamente ver mi vida, ver mi línea, sino que en algún momento de la vida tengo que mirar al lado mío y ver quien está".

Es evidente que existe una estructuración que implica un punto de inicio y la proyección o visualización de la continuidad. El camino posee un sitio de comienzo y quien inicia su recorrido alberga la esperanza de llegar a otro lugar o "punto final". Esta metáfora genera otra que, si bien puede estructurarse bajo esta misma conceptualización, se opta por aislarla por la contundencia en las narraciones: el estudio es un camino.

El estudio es un camino: En el recorrido de este camino hay una serie de momentos; hay que dar pasos o caminar, desplazarse de un lugar a otro, partir de un punto cercano al individuo que comenzará la travesía (punto inicial); hay que dar el primerpaso. En esa línea educativa o camino educativo se encantarán tramos medios e incluso dificultades que hacen que el caminante se resbale; esto con el tesón se supera para llegar al punto final, para terminar o finalizar, para coronar la meta visualizada.

Por la trascendencia que las mujeres le dan al estudio como temática digna de narrar y experiencia valiosa, ellas utilizan más que los hombres esta clase de metáforas. Obsérvese: "siempre me visualicé a llegar muy lejos, a llegar muy lejos a nivel educativo, siempre pensé terminar quinto, terminar el colegio, terminar bachillerato y llegar a la universidad"; "es el momento en el que culminé mi primera etapa de, de academia cuando me pude graduar" Para ellas en este camino hay tramos difíciles que se pueden superar: "tuve que realizar muchos esfuerzos para poder entrar, me gradué del colegio y me presenté varias veces, me presenté cinco veces"; "esos acontecimientos me ponían muy mal y yo siempre seguía insistiendo, seguía insistiendo en para mi seguir, luchar por ese sueño era lo más importante. Esto conlleva a ver que el estudio tiene gran valor por el fuerzo y la lucha que hay que librar en ese camino: "la educación en mi familia ha sido una de las primeras, o de los primeros principios que han implantado".

Los hombres estructuran este concepto de la siguiente manera: "siguiendo esa línea educacional"; "vi culminado un proceso que inició en esa Institución"; "yo ahora cerrando ese ciclo universitario pues me doy cuenta que (...)"; los académicos determinaron que pues el 
proceso había sido mucho más eeeh avanzado o satisfactorio en mi caso". Tanto para hombres como para las mujeres se trata de un proceso, en el cual iniciarlo es tan importante como su terminación; cada terminación es un nuevo inicio y un complemento de ese proceso; un avance hacia una meta trazada, al final del camino.

En el capitalismo académico, el estudio es la mejor herencia que le pueden dejar los padres a sus hijos; hace parte de la gran metáfora de la modernidad (Boudieu, 1980). El conocimiento, más que un valor de uso, tiene un valor de cambio fundamental en el mercado. El conocimiento da poder, prestigio, ascenso, y como lo enuncian los relatos de mujeres y hombres, parece convertirse en el camino fundamental para salir adelante. Sin duda, el conocimiento, en la época actual, se convierte en la principal fuerza productiva de la sociedad.

La vida es una lucha/guerra: Esta metáfora permite conceptualizar la vida en términos de algo que sucede inmediata y espontáneamente en la vida cotidiana, a saber, un conflicto físico. En las sociedades capitalistas, en vías de desarrollo, para mencionar una de las tantas metáforas que designan este tipo de culturas, se ha convertido en natural que los individuos luchen, menos por vivir que por sobrevivir, por solucionar las urgencias del día a día allende las posibilidades de reflexión y pensamiento crítico. Es decir, entre más ocupados estén los individuos en solucionar lo inmediato, menos posibilidades de pensar, reflexionar y comprender los problemas complejos de la sociedad, vía transformación. Como lo enuncian reiteradamente los relatos, tanto hombres como mujeres conceptualizan la vida como una guerra, una batalla cotidiana, un enfrentamiento diario, en donde hay unos que ganan y otros que pierden.

Al conceptualizar la vida de este modo, el narrador establece una relación de semejanza entre el dominio origen lucha, guerra y el domino meta vida. Según El RAE la lucha se define como "una pelea en que dos personas se abrazan con el intento de derribar una a otra; lid, combate, contienda, disputa"; en sentido figurado como "oposición, rivalidad u hostilidad entre contrarios que tratan de imponerse el uno al otro; esfuerzo que se hace para resistir a una fuerza hostil o a una tentación, para subsistir o para alcanzar algún objetivo"

Todos se refieren a la vida como a una lucha y un conflicto que hay que afrontar: relatos de mujeres: "yo presenté nuevamente el ICFES (...) fue una lucha tenaz pues había mucha competencia".

La vida es una balanza: Las mujeres conciben la vida en términos de la balanza. La vida como un objeto que hay que saber equilibrar para llevar a cabo logros: "Me siento incompleta porque yo quisiera tener ese equilibrio en mi familia y no lo hay (...)"; "Uno siempre necesita digamos del apoyo de una parte masculina y una parte femenina (...)" "Pensé que se me iba a caer el mundo encima". La siguiente metáfora aparece solamente en un relato masculino: "anhelar un entorno nacional un poquito más estable"; sin embargo, en los distintos relatos se observan búsquedas de armonía: para las mujeres estudiar y estar en relación con una familia, y para los hombres viajar.

La vida es un edificio: Las mujeres comparan el trasegar por la vida con la construcción de un edificio: un edificio se va construyendo poco a poco; hay que colocarle buenas bases para que no se derrumbe; puede tener cambios y transformaciones; por consiguiente, la vida de las personas o las personas se van construyendo lentamente en la medida que avanza el tiempo; el hombre debe tener buenas bases o valores, buena formación desde el principio para que no se 
derrumbe o desvíe de su cauce; el hombre cada vez se transforma, sufre cambios, no es estático: "Cuando tú piensas en el tipo de amistades que vas a tener, piensas si esas personas te van ayudar a construir como personas, desde la perspectiva que tú buscas (...).

\section{Conclusiones.}

En relación con la primera pregunta planteada al inicio del trabajo, puede afirmarse que no existen diferencias significativas en la forma de estructurar, adjetivar y evaluar los relatos entre hombres y mujeres; quizá donde hubo mayor diferencia fue en los temas que abordan, específicamente en la forma de enfocarlos u orientarlos.

En este aspecto llama la atención que la tendencia de las mujeres es a desarrollar narraciones con temáticas que implican aspectos negativos como la muerte, vicios, enfermedades, rupturas y en general obstáculos.

Un aspecto diferenciador de género entre hombres y mujeres jóvenes lo constituye el tratamiento que le dan al estudio, la educación y la formación; para ellas definen su proyecto de vida, para los hombres definen un momento de su vida. Desde esta óptica la mujer se convierte en protagonista de estos procesos en cuanto se ve como persona que puede aportar a la educación como educadora y como madre. Esto se entiende no explícitamente, sino que se infiere de las construcciones metafóricas para referir esta realidad. La temática que marca diferencia entre hombres y mujeres son los viajes.

Se percibe que culturalmente, a los hombres se les ha asignado la condición de ser de la calle y aventureros, lo cual corrobora lo hallado en el análisis de las metáforas; al contrario, a las mujeres se les asignan lugares más íntimos y privados como la casa, el colegio y la universidad; su rol de madres, esposas y educadoras no les permiten esa movilidad y desplazamiento aventurero.

Los relatos de hombres narran situaciones que, aunque constituyan temática precisas e importantes, se tornan eventos con un matiz anecdótico y circunstancial, mientras que los relatos femeninos con temáticas igualmente trascendentales son narrados ya no como anécdotas, sino como asuntos esenciales en sus vidas o de la vida en general. Es decir que la diferencia, cuando se abordan temáticas similares, no está en el tema sino en la forma de narrar y en el enfoque, que se le da a lo dicho. En cuanto al uso de la categoría adjetivo como manera de expresar sentimientos y emociones, se relativiza el imaginario (o incluso las conclusiones de investigaciones) que dice que las narraciones de las mujeres están más impregnadas de carga sentimental y afectiva que las de los hombres. Del mismo modo se matiza la idea de que a la hora de narrar las mujeres son más prolijas.

En relación con la segunda pregunta puede concluirse que las metáforas constituyen un sistema conceptual y un mecanismo primario para la comprensión humana y por lo mismo, un mecanismo potente para desestabilizar y crear nuevos significados y realidades en nuestras vidas.

Las sociedades no avanzan solas, sin sujetos; progresan, retroceden, legitiman/deslegitiman porque existen allí sujetos psicosociales que piensan, dicen y hacen. Los anteriores aspectos, permiten, una vez más poner en tensión algunas visiones objetivistas y deterministas de la sociedad, el lenguaje, el significado y la verdad.

\begin{tabular}{l|l|l|l|l|l|l} 
AGO.USB & Medellín - Colombia & Vol. 17 No. 1 & PP 1 - 323 & enero - junio & 2017 & ISSN: 16578031
\end{tabular} 
La investigación permitió, de esta manera, desvelar aquellas formas de decir y actuar que socialmente hombres y mujeres van estructurando y naturalizando vía comunicación e interacción social.

El análisis metafórico permitió identificar y comprender aquellos fenómenos de la cultura que los sujetos han asimilado de forma práctica y espontánea, sin confrontar y problematizar. Los resultados permiten la reflexión al indicar que es necesario, vía pensamiento crítico, confrontar los esquemas y metáforas convencionales que lucen naturales, pero ocultan internamente dispositivos ideológicos de control. El fin último de la investigación es la reflexión, y la posible transformación de representaciones, metáforas y prácticas. Confrontar y asimilar que otra forma de pensar, decir y actuar es posible, es el camino para posibles transiciones y cambios en la cultura.

\section{Bibliografía.}

Bajtin, M. (1982). Estética de la creación verbal. México: Siglo Veintiuno Editores.

Bourdieu, P. (1980). El sentido Práctico. Argentina: Siglo Veintiuno Editores.

Deleuze, G. (1989). Lógica del sentido. España: Paidós.

Díaz, H. (2006). La metáfora en la definición científica. En M. Di Stefano , Metáforas en uso. Argentina: Editorial Biblos.

Freire, P. (2004). La importancia de leer y el proceso de liberación. México: Siglo XXI Editores.

Grice, H. P. (1991). Las intenciones y el significado del hablante . En L. M. Valdéz Villanueva, La búsqueda del significado. Lecturas de filosofía del lenguaje (págs. 481- 510). Madrid: TecnosUniversidad de Murcia.

Jodelet, D. (1984). En S. Moscovici, Psicología social II. España: Paidós.

Labov, W. (1988). La transformación de la experiencia en sintaxis narrativa. Cali: Centro de traducciones - Universidad del Valle.

Lakoff, G., \& Johnson, M. (2004). Metáforas de la vida cotidiana. Madrid: Cátedra.

McLaren , P. (1997). Pedagogía crítica y cultura depredadora. España: Paidós.

Moscovici, S. (1984). Psicología Social II. España: Paidós.

Nietzsche, F. (2000). Introducción teorética acerca de la verdad y la mentira en el sentido extramoral. En El libro del filósofo seguido de retórica y lenguaje. Madrid: Taurus.

Peirce, C. (1987). Obra lógico semiótica. Madrid: Taurus.

Ricoeur, P. (1981). Paul Ricoeur hermeneutics and the buman sciences. (J. B. Thompson, Ed.) New York: Cambridge University Press. 
Soler C, S. (2004). Discurso y género en historias de vida. Una investigación de relatos de hombres y mujeres en Bogotá. Bogotá: I.C.C.

VanDijk, T. A. (2000). El discurso como interacción en la sociedad. España: Editorial Gedisa . 